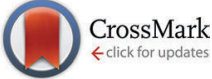

Cite this: Phys. Chem. Chem. Phys., 2015, 17, 10953

Received 16th January 2015, Accepted 14th March 2015

DOI: $10.1039 / \mathrm{c5cp00268k}$

www.rsc.org/pccp

\title{
Laboratory study on $\mathrm{OH}$-initiated degradation kinetics of dehydroabietic acid $\dagger$
}

\author{
Chengyue Lai, Yongchun Liu, * Jinzhu Ma, Qingxin Ma and Hong He*
}

\begin{abstract}
Dehydroabietic acid (DHAA) is a specific organic tracer for the pyrolysis of conifer resin. To understand its atmospheric stability, the degradation behavior of particulate DHAA in the presence of hydroxyl radicals $(\mathrm{OH})$ was investigated under different environmental conditions using a stainless steel reactor with volume of $30 \mathrm{~cm}^{3}$, in the dark. At $25{ }^{\circ} \mathrm{C}$ and $40 \%$ relative humidity $(\mathrm{RH})$, the second-order rate constant $\left(k_{2}\right)$ of pure DHAA with $\mathrm{OH}$ was measured to be $5.72 \pm 0.87 \times 10^{-12} \mathrm{~cm}^{3}$ molecule $\mathrm{s}^{-1}$. The influence of temperature, $\mathrm{RH}$ and mixing state on the degradation kinetics of DHAA were also investigated. At $40 \% \mathrm{RH}, k_{2}$ of pure DHAA increases with increasing temperature and follows the Arrhenius equation $k_{2}=(8.9 \pm 1.9) \times 10^{-10} \exp [-(1508.2 \pm 64.2) / T]$, while $\mathrm{RH}$ does not have significant impact on $k_{2}$ at $25{ }^{\circ} \mathrm{C}$. At $25{ }^{\circ} \mathrm{C}$ and $40 \% \mathrm{RH}$, compared with pure DHAA, the corresponding $k_{2}$ for DHAA mixed with $\left(\mathrm{NH}_{4}\right)_{2} \mathrm{SO}_{4}$ decreased to $4.58 \pm 0.95 \times 10^{-12} \mathrm{~cm}^{3}$ molecule ${ }^{-1} \mathrm{~s}^{-1}$, while the value was $3.30 \pm 0.79 \times 10^{-12} \mathrm{~cm}^{3}$ molecule ${ }^{-1} \mathrm{~s}^{-1}$ when mixed with soot. The atmospheric lifetime of DHAA varied from $2.3 \pm 0.2$ to $4.4 \pm 0.8$ days under different environmental conditions. This study indicates that degradation of DHAA by $\mathrm{OH}$ radicals is appreciable, and a significant error in source apportionment should be introduced if the contribution of degradation to DHAA concentration is not considered during air mass aging.
\end{abstract}

\section{Introduction}

Organic aerosols contain significant fractions of fine particles, and hundreds of thousands of individual organic species derived from biogenic, anthropogenic and photochemical sources. ${ }^{1,2}$ These aerosols affect the radiation budget of Earth, and can cause adverse health effects on humans. ${ }^{3}$ Therefore, to protect both human health and the environment, it is important to control the emissions at the source and implement effective reduction measurements on local, regional and global scales. ${ }^{4,5}$ Comprehensive investigations are required to evaluate which sources contribute to the total mass of organic aerosols. ${ }^{6,7}$ Source apportionment techniques, such as chemical mass balance $(\mathrm{CMB})$ and positive matrix factorization (PMF) receptor models, have been developed and used successfully for quantitative identification of sources for organic pollutants in aerosols. ${ }^{8-13}$ In both $\mathrm{CMB}$ and PMF models, concentrations of tracers to $\mathrm{PM}_{2.5}$ and total organic carbon for different sources are crucial

State Key Joint Laboratory of Environment Simulation and Pollution Control, Research Center for Eco-Environmental Sciences, Chinese Academy of Sciences, Beijing, 100085, China.E-mail: ycliu@rcees.ac.cn, honghe@rcees.ac.cn $\dagger$ Electronic supplementary information (ESI) available: Including detailed experimental procedures for $\mathrm{OH}$ determination, preparation procedures for the mixed samples, discussions about the diffusion corrections, a table about the size of mixed samples and figures about the set-up and the mixed sample images. See DOI: $10.1039 / \mathrm{c} 5 \mathrm{cp} 00268 \mathrm{k}$ as input parameters. Organic tracers are becoming more commonly used as source indicators because they are specific to the sources of pollutants. ${ }^{14}$

Biomass burning is one of the main sources of fine primary carbonaceous aerosols in the form of organic carbon (OC) and black carbon (BC) on the global scale. ${ }^{15}$ The emissions from biomass burning are estimated to contribute up to $38 \%$ of tropospheric $\mathrm{O}_{3}, 39 \%$ of particulate organic carbon and more than $86 \%$ of elemental carbon. ${ }^{16-18}$ Biopolymers such as cellulose, lignin, hemicellulose, suberlin, sporopollenin, chitin, etc. are the major constituents of the biomass. ${ }^{19}$ Dehydroabietic acid (DHAA, chemical structure shown in Fig. 1) is a main component of particles emitted through biomass burning. It is the major marker compound emitted from conifer fuel combustion, and can be used to distinguish softwood from hardwood combustion. ${ }^{19-22}$ As coniferous tree species represent an important fraction of regional forest composition, DHAA can be emitted from both residential heating and wildfires. ${ }^{23,24}$ The detritus of conifer wood burning smoke can also be oxidized

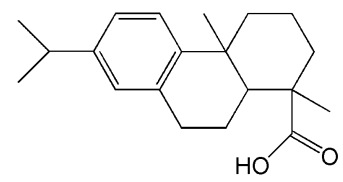

Fig. 1 Chemical structure of dehydroabietic acid (DHAA) 
to DHAA, making it the key tracer for the air mass affected by conifer burning. ${ }^{25}$ In addition to the natural sources, some anthropogenic sources can also emit DHAA, such as the pulp and paper industry, as well as production of commercial disproportionated rosin. DHAA can be detected easily in the atmosphere, ${ }^{17,26-28}$ and some studies have found similar concentration levels of DHAA in the atmosphere compared with another organic tracer, levoglucosan. ${ }^{5}$ Because of its ubiquity in the atmosphere and specificity for conifer combustion, DHAA has recently been used as a molecular tracer in source apportionment. ${ }^{25,29-35}$ DHAA also represents a series of compounds which make up high proportions of organic aerosols in the atmosphere.

A basic assumption in source apportionment models is that the tracers should have sufficient stability to persist in the atmosphere. In previous studies, particle-phase biomass burning tracers were all thought to be sufficiently stable, ${ }^{35}$ but a few recent studies have indicated that some tracers have high reactivity to oxidizing radicals, based on chamber experiments, field observations ${ }^{1,32,36-43}$ and quantum chemical calculations. ${ }^{44-46}$ As for DHAA, there are only limited studies which have investigated its photolysis degradation in water ${ }^{47}$ and biodegradation in the environment by microorganisms. ${ }^{48}$ Leithead et al. also pointed out that DHAA may be unstable in the atmosphere. ${ }^{31}$ Using quantum chemical methods, Bai et al. investigated the reaction mechanism and rate constants for $\mathrm{DHAA}-\mathrm{OH}$ and $\mathrm{DHAA}-\mathrm{O}_{3}$ reactions in the gas phase. ${ }^{49}$ However, to date, there have been no laboratory studies focusing on heterogeneous reactions between DHAA and $\mathrm{OH}$ radicals.

Tropospheric temperature varies notably with the change of seasons. Some studies have found that temperature can affect the reactions between different organic compounds and $\mathrm{OH}$ radicals. ${ }^{50,51}$ For this reason, it is necessary to investigate the effect of temperature on the DHAA-OH reaction for evaluation of the atmospheric lifetime of DHAA. Relative humidity ( $\mathrm{RH})$ is variable from $20 \%$ to $90 \%$ in most areas of the world, which may influence the reaction between organics and $\mathrm{OH}^{52}$ Therefore, to study the $\mathrm{RH}$ effect on DHAA degradation kinetics by $\mathrm{OH}$, is also necessary to understand the atmospheric behavior of DHAA. Furthermore, in the real atmosphere, organic compounds will mix with other particulate components during transport, which can alter their reactivity toward oxidants. For instance, the heterogeneous reactivity of benzo $[a]$ pyrene $(\mathrm{BaP})$ toward $\mathrm{O}_{3}$ was reduced substantially by a thin $(4-8 \mathrm{~nm})$, solid eicosane coating and entirely suppressed by thick (10-80 nm) solid eicosane coatings; ${ }^{53}$ the uptake coefficient of $\mathrm{N}_{2} \mathrm{O}_{5}$ on mixtures of humic acid and $\left(\mathrm{NH}_{4}\right)_{2} \mathrm{SO}_{4}$ decreased by more than a factor of two compared with that of single-component $\left(\mathrm{NH}_{4}\right)_{2} \mathrm{SO}_{4} \cdot{ }^{54}$ During biomass burning, a number of air pollutants will be generated, with soot being one of the most significant. ${ }^{55}$ Furthermore, $\left(\mathrm{NH}_{4}\right)_{2} \mathrm{SO}_{4}$ also constitutes a significant fraction of the total atmospheric particulate mass. ${ }^{56}$ It has been found that soot particles can be internally mixed with sulfate. ${ }^{57,58}$ These particulate components are likely to mix with DHAA in the ambient atmosphere, thus must be considered when carrying out DHAA degradation studies.
In this study, we present the measured heterogeneous degradation kinetics of particulate dehydroabietic acid exposed to $\mathrm{OH}$ radicals under different environmental conditions. The aim of this work is to obtain experimental degradation kinetic parameters and atmospheric lifetimes of DHAA, and further understand the influence of temperature, relative humidity and mixing states on the degradation kinetics. The results obtained in this study will provide an update for kinetic parameters of DHAA in the atmosphere, and provide important information for possible model investigations, especially for source apportionment studies.

\section{Experimental section}

\section{Experimental methods}

All the experiments were performed using a flow system, which contains a quartz tube irradiated with UV light for $\mathrm{OH}$ generation and a stainless steel reactor for dark reaction. The interior walls of the reactor were coated with Teflon to provide a chemically inert surface. The volume of the reactor was $30 \mathrm{~cm}^{3}$. A Teflon disc (geometric surface area $3.39 \mathrm{~cm}^{2}$ ) was used as the sample holder. The schematic diagram of the experimental set-up used in this study is shown in Fig. S1 (ESI $\dagger$ ). For the kinetic studies of pure DHAA, $10.0 \pm 0.1 \mu \mathrm{g}$ of DHAA dry film was placed on the disc, which was generated evenly by gently drying a DHAA/ methanol solution with $\mathrm{N}_{2}$ flow. In the case of reactions for the mixed samples, $10.0 \pm 0.1 \mathrm{mg}$ of each sample was placed evenly on the disc. Although the DHAA in this study was presented in film form rather than as suspended particles, previous studies have confirmed the feasibility of this method in investigation of the degradation kinetics of levoglucosan and heterogeneous reactions between $\mathrm{O}_{3}$ and anthracene or $\mathrm{NO}_{2}$ and anthracene adsorbed on mineral oxides. ${ }^{59-61}$

The reactions between DHAA and $\mathrm{OH}$ were carried out under mixed air flow with a constant $\mathrm{OH}$ concentration. The total flow rate was $300 \mathrm{~mL} \min ^{-1}$ with simulated air $\left(80 \%\right.$ high purity $\mathrm{N}_{2}$ and $20 \%$ high purity $\mathrm{O}_{2}$ ) and bubbled $\mathrm{H}_{2} \mathrm{O}_{2}$ flow. The $\mathrm{RH}$ of the system was controlled by varying the ratio of wet $\mathrm{N}_{2}$ flow, which was achieved by bubbling nitrogen through $\mathrm{H}_{2} \mathrm{O}$, to dry $\mathrm{N}_{2}$ flow, and determined using a humidity temperature meter (CENTER314) at the exit of the reactor. The temperature of the system was controlled by a circulating water bath (CCA-20, Gongyi City YUHUA Instrument Co., Ltd) with uncertainty less than $0.5{ }^{\circ} \mathrm{C}$. The water partial pressure in the system may change when the temperature changes, but RH can be kept constant at different temperatures by adjusting the ratio of wet $\mathrm{N}_{2}$ flow to dry $\mathrm{N}_{2}$ flow. As direct irradiation of the samples by UV light was avoided (as shown in Fig. S1, ESI $\dagger$ ), any decay of reactants should result from oxidation by $\mathrm{OH}$ radicals in the dark.

Reacted samples were ultrasonically extracted using $20.0 \pm$ $0.1 \mathrm{~mL}$ methanol, and then filtered using a glass fiber filter that had been previously cleaned by methanol. The eluate was evaporated to near dryness, and subsequently transferred into a $1.5 \mathrm{~mL}$ sealed vial, then dried to residue under a gentle nitrogen stream. 
The high polarity of DHAA demands a derivatization step prior to GC analysis, and silylation is recognized as the best derivatization method to reduce the polarity. ${ }^{62} \mathrm{~N}, \mathrm{O}$-Bis-(trimethylsilyl)trifluoroacetamide (BSTFA) plus 1\% trimethylchlorosilane (TMCS) was chosen to be the silylation reagent for the derivatization of DHAA. In this study, $50 \mu \mathrm{L}$ of pyridine and $50 \mu \mathrm{L}$ of BSTFA plus $1 \%$ TMCS were added to the residue from the previous steps, and the silylation reaction was performed at $60{ }^{\circ} \mathrm{C}$ for 60 minutes. Finally, $1.0 \mu \mathrm{L}$ of the silylated product was injected into the GC-MS system.

GC was performed with an Agilent Technology 6890N Network GC System, and MS was carried out with an Agilent Technology 5973 Network system with Mass Selective Detector. The capillary column HP-5MS (30 m, $0.25 \mathrm{~mm}$ internal diameter, $0.25 \mu \mathrm{m}$ film thickness) was installed in the GC, and its output was inserted directly into the ion source of the MS. Each sample was introduced via EPC splitless mode injection. The oven temperature was held at $80{ }^{\circ} \mathrm{C}$ for $1 \mathrm{~min}$, then programmed to $250{ }^{\circ} \mathrm{C}$ at a ramp of $12{ }^{\circ} \mathrm{C} \min ^{-1}$ and held at $250{ }^{\circ} \mathrm{C}$ for $2 \mathrm{~min}$. Helium was used as carrier gas at a constant flow rate of $1.0 \mathrm{~mL} \mathrm{~min}^{-1}$. The temperatures of the injector and transfer line were $250{ }^{\circ} \mathrm{C}$ and $280{ }^{\circ} \mathrm{C}$, respectively. For quantification of DHAA, mass detection was performed in selected ion monitoring (SIM) mode. The $\mathrm{m} / \mathrm{z}$ at 239 was used as the quantification ion and the $\mathrm{m} / \mathrm{z}$ at 357 and 372 were used as the confirmation ions for the trimethyl silylation product of DHAA, respectively. The concentration of DHAA was measured based on an external standard and use of a calibration curve.

\section{OH generation and detection}

$\mathrm{OH}$ radicals were generated in a quartz tube by UV photolysis of $\mathrm{H}_{2} \mathrm{O}_{2}$. Two ultraviolet light lamps $(18 \mathrm{~W}$, Beijing Lighting Research Institute) which provided UV radiation with a central wavelength around $254 \mathrm{~nm}$ were used. The concentration of $\mathrm{OH}$ radical was controlled by varying the ratio of pure $\mathrm{N}_{2}$ and $\mathrm{H}_{2} \mathrm{O}_{2}$ flow passing through the tube.

Salicylic acid has strong reactivity with $\mathrm{OH}$ radicals, and can be used to trap them. ${ }^{63}$ In this study, the yields of the products (2,3-dihydroxybenzonic acid and 2,5-dihydroxybenzonic acid) during the reactions between salicylic acid and $\mathrm{OH}$ were used to estimate the concentration of near-surface $\mathrm{OH}$ radicals. To determine $\mathrm{OH}$ concentration, the reactions for salicylic acid oxidation occurred concurrently with DHAA oxidation. Detailed descriptions of the experimental procedures for $\mathrm{OH}$ determination are given in the ESI. $\dagger$ This method is usually used for liquid phase $\mathrm{OH}$ determination, but has been verified in our previous work as the measured $k_{2}$ of levoglucosan toward hydroxyl radical is comparable with literature values. ${ }^{59}$ In this study, the $\mathrm{OH}$ concentration was adjusted to $2.05 \pm 0.06 \times 10^{7}$, $2.38 \pm 0.08 \times 10^{7}$ and $2.99 \pm 0.10 \times 10^{7}$ molecules $\mathrm{cm}^{-3}$ for subsequent experiments. Repeat experiments were carried out seven times for each $\mathrm{OH}$ concentration. The relative standard deviations (RSD) of $\mathrm{OH}$ concentration were less than $10 \%$.

\section{Mixed sample preparation and characterization}

To simulate different mixing states, DHAA was mixed with $\left(\mathrm{NH}_{4}\right)_{2} \mathrm{SO}_{4}$ and soot particles. In this study, the symbol A-B represents $\mathrm{A}$ internally mixed with $\mathrm{B}$, and the symbol $\mathrm{A} / \mathrm{B}$ represents A coated on $\mathrm{B}$. Before being mixed with DHAA, $\left(\mathrm{NH}_{4}\right)_{2} \mathrm{SO}_{4}$ was cleaned by ultrasonication in methanol, followed by drying at room temperature, and soot particles were preheated at $300{ }^{\circ} \mathrm{C}$ under $\mathrm{N}_{2}$ protection for $8 \mathrm{~h}$. DHAA was mixed with the particles via an impregnation method. Detailed preparation procedures for the mixed samples are given in the ESI. $\dagger$ Three mixed samples were prepared to simulate different mixing states: DHAA- $\left(\mathrm{NH}_{4}\right)_{2} \mathrm{SO}_{4}$ (DHAA-AS), DHAA/soot, and DHAA$\left(\mathrm{NH}_{4}\right)_{2} \mathrm{SO}_{4} /$ soot (DHAA-AS/soot). To maintain a consistent initial concentration of DHAA, $10.0 \mu \mathrm{g}$ of DHAA was used for each experiment. All the mixed samples were dried at room temperature and stored at $-18{ }^{\circ} \mathrm{C}$ in the dark.

The mixing state and particle size of the mixed samples were characterized by a scanning electron microscope (SEM, Hitachi SU8000 with an accelerating voltage of $10 \mathrm{kV}$ ) and a transmission electron microscope (TEM, Hitachi H-7500 with an acceleration voltage of $80 \mathrm{kV}$ ). The SEM and TEM results are shown in Fig. S2 (ESI $\dagger$ ). The measured particle size of the mixed samples varied from $52.1 \pm 18.7$ to $217.6 \pm 95.7 \mathrm{~nm}$ (shown in Table S1, ESI $\dagger$ ). To understand the surface state of the mixed samples, SEM with X-ray microanalysis (SEM-EDX, Hitachi SU8000 with an accelerating voltage of $30 \mathrm{kV}$ ) was also used to semi-quantitatively detect the element composition on the surface of DHAA-AS.

\section{Chemicals}

All the chemicals were of chromatographic grade and used without further purification. Methanol was obtained from Fisher Scientific. A standard of dehydroabietic acid was purchased from AccuStandard, Inc. N,O-Bis-(trimethylsilyl) trifluoroacetamide plus trimethylchlorosilane (BSTFA:TMCS $=99: 1$ ) and salicylic acid (>99.5\%) were purchased from Tokyo Chemical Industry Co., Ltd. Pyridine, $\left(\mathrm{NH}_{4}\right)_{2} \mathrm{SO}_{4}$ and $30 \% \mathrm{H}_{2} \mathrm{O}_{2}$ were purchased from Sinopharm Chemical Reagent Co., Ltd. Printex U powder from Degussa (CAS No.: 1333-86-4) was used as a model soot aerosol in this study. This was produced through incomplete combustion of hydrocarbons in the air. ${ }^{64,65}$ Its specific surface area is $97.24 \mathrm{~m}^{2} \mathrm{~g}^{-1}$, measured using nitrogen Brunauer-EmmettTeller (BET) physisorption (Quantachrome Autosorb-1-C). To better understand the size of soot particles, SEM was used (Hitachi SU8000 with an accelerating voltage of $1.0 \mathrm{kV}$ ). Images are shown in Fig. S4 (ESI $\dagger$ ). The average sizes of soot particles was measured to be $39.8 \pm 10.5 \mathrm{~nm}$. High purity $\mathrm{N}_{2}(99.99 \%)$ and $\mathrm{O}_{2}(99.99 \%)$ were supplied by Beijing HUAYUAN Gases Inc.

\section{Results and discussion}

\section{Kinetic measurements for pure dehydroabietic acid}

To evaluate the influence of vaporization and degradation by $\mathrm{H}_{2} \mathrm{O}_{2}$ on dehydroabietic acid, blank experiments were performed under the same air and $\mathrm{H}_{2} \mathrm{O}_{2}$ flows as those in the oxidation experiments at different temperatures. The experiments were carried out at $40 \% \mathrm{RH}$ in the dark. As shown in Fig. S5 (ESI $\dagger$ ), the decrease in the amount of pure dehydroabietic 
acid was less than $10 \%$ at $5{ }^{\circ} \mathrm{C}$ and $30{ }^{\circ} \mathrm{C}$ over 5 hours purging. The experiments in this study were all carried out in the temperature range between $5{ }^{\circ} \mathrm{C}$ and $30{ }^{\circ} \mathrm{C}$. Therefore, the slight decrease of DHAA concentration can be ascribed to evaporation of DHAA during purging by air flow. This DHAA evaporation will not prominently affect the measured reaction rate because of its relatively low content, and this effect has been considered in the kinetics interpretation.

To determine the degradation rate constant of pure DHAA toward $\mathrm{OH}$ radicals, pure DHAA was oxidized under three different $\mathrm{OH}$ concentrations (near-surface gas phase concentration, similarly hereinafter), which had been estimated previously in degradation experiments of salicylic acid. The $\mathrm{OH}$ concentrations used in this study were $2.05 \pm 0.06 \times 10^{7}, 2.38 \pm 0.08 \times 10^{7}$ and $2.99 \pm 0.10 \times 10^{7}$ molecules $\mathrm{cm}^{-3}$.

The kinetic data were determined by monitoring the loss of DHAA concentration as a function of $\mathrm{OH}$ exposure at $25{ }^{\circ} \mathrm{C}$ with $40 \% \mathrm{RH}$ in the dark. Assuming a second-order reaction between $\mathrm{OH}$ and DHAA, the loss rate of DHAA can be expressed as follows,

$$
-\frac{\mathrm{d}[\mathrm{DHAA}]}{\mathrm{d} t}=k_{2}[\mathrm{OH}][\mathrm{DHAA}]
$$

where $[\mathrm{OH}]$ is the near-surface $\mathrm{OH}$ concentration (molecules $\mathrm{cm}^{-3}$ ), [DHAA] is the concentration of dehydroabietic acid and $k_{2}$ is the second-order rate constant for the reactions between DHAA and $\mathrm{OH}\left(\mathrm{cm}^{3}\right.$ molecule $\left.{ }^{-1} \mathrm{~s}^{-1}\right)$. As the experiments were performed under steady state conditions with constant $\mathrm{OH}$ concentration, eqn (1) can be integrated from zero to the residence time $(t)$ of reactants:

$$
\ln \frac{[\mathrm{DHAA}]}{[\mathrm{DHAA}]_{0}}=-k_{2}[\mathrm{OH}] t
$$

where $[\mathrm{DHAA}]_{0}$ is the initial concentration of dehydroabietic acid. As DHAA cannot be consumed completely, even under high $\mathrm{OH}$ exposure, a plateau is always observed in the degradation curve of DHAA. This phenomenon has been widely observed for other reaction systems. ${ }^{43,66}$ This plateau might result from the diffusion limit of $\mathrm{OH}$ in the solid phase and the influence of oxidation products remaining on the surface. The fraction of DHAA remaining (at the plateau) decreases with increased $\mathrm{OH}$ concentration, which may be a result of more $\mathrm{OH}$ radicals diffusing into DHAA at the beginning of the reaction after some oxidation products are further oxidized to small molecules with high vapor pressure, which may cause a vacancy on the surface for $\mathrm{OH}$ reaction under higher $\mathrm{OH}$ concentrations.

Fig. 2 shows the changes in $[\mathrm{DHAA}] /[\mathrm{DHAA}]_{0}$ as a function of $\mathrm{OH}$ exposure under different $\mathrm{OH}$ concentrations at $40 \% \mathrm{RH}$ and $25{ }^{\circ} \mathrm{C}$. The lines are the exponential curve fitting results, from which the $k_{2}$ can be derived via eqn (2). The $k_{2}$ values under different $\mathrm{OH}$ concentrations are listed in Table 1. In general, for the heterogeneous reaction taking place under ambient pressure and on packed powder samples, both external (gaseous reactants from gas phase to the surface) and internal diffusions (from the surface layer to the underneath layers and
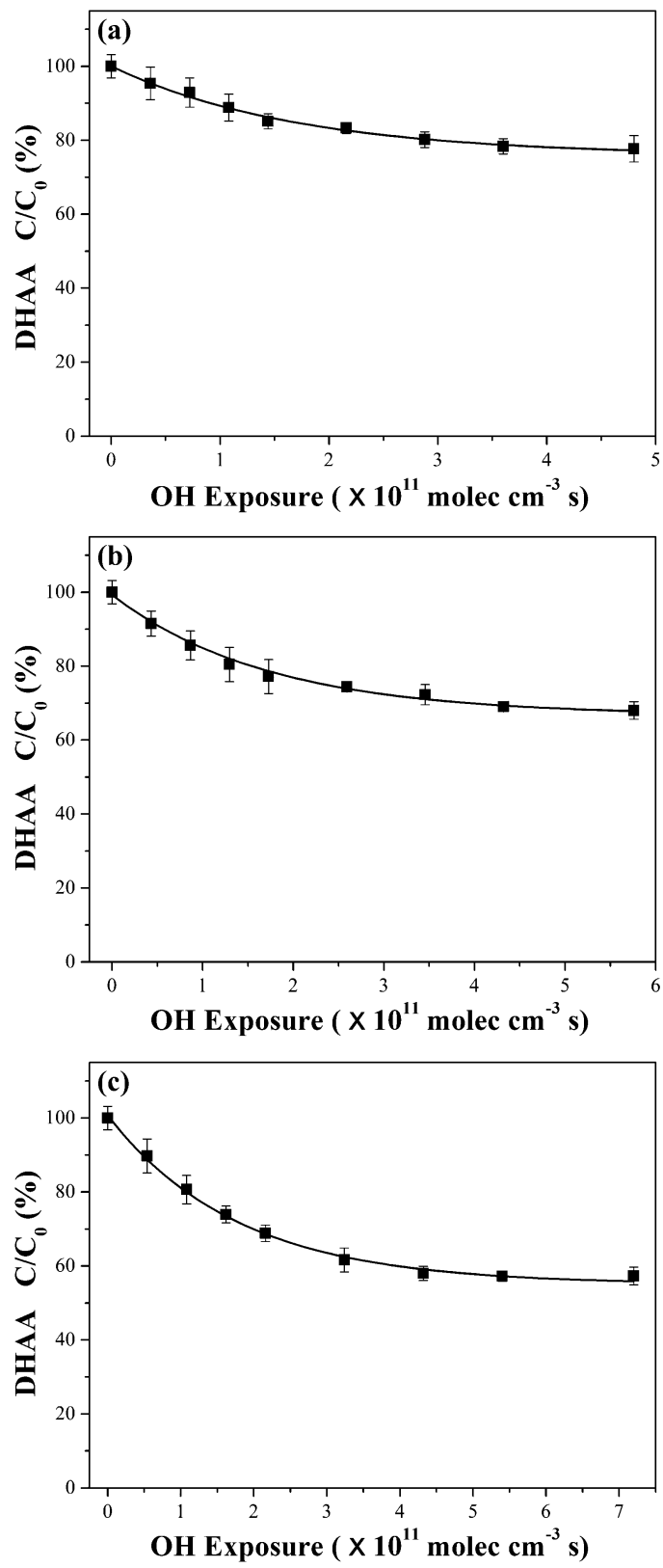

Fig. 2 Representative decays for dehydroabietic acid under different $\mathrm{OH}$ concentrations at $25^{\circ} \mathrm{C}$ and $40 \% \mathrm{RH}(n=3$, error bars represent 1 standard deviation based on triplicate analyses). (a) $[\mathrm{OH}]=(2.05 \pm 0.06) \times$ $10^{7}$ molecules $\mathrm{cm}^{-3}$; (b) $[\mathrm{OH}]=(2.38 \pm 0.08) \times 10^{7}$ molecules $\mathrm{cm}^{-3}$; (c) $[\mathrm{OH}]=(2.99 \pm 0.10) \times 10^{7}$ molecules $\mathrm{cm}^{-3}$. Samples were exposed to $\mathrm{OH}$ radicals from 0 minutes to 400 minutes $(0 \mathrm{~min}, 30 \mathrm{~min}, 60 \mathrm{~min}, 90 \mathrm{~min}$, $120 \mathrm{~min}, 180 \mathrm{~min}, 240 \mathrm{~min}, 300 \mathrm{~min}$ and $400 \mathrm{~min}$ for each point).

into the pores of particles or films) need to be corrected. ${ }^{67-69}$ However, as discussed in detail in the ESI, $\dagger$ it is not necessary to do both external and internal diffusion corrections for the following reasons. Firstly, the near-surface but not gas phase $\mathrm{OH}$ concentrations were measured with a particle phase reference. Secondly, all the samples are nonporous with smooth surfaces. Finally, previous studies have recognized that reactions between $\mathrm{OH}$ and organic compounds are limited on the surface. ${ }^{71}$ 
Table 1 Calculated rate constant and atmospheric lifetime of dehydroabietic acid for the reaction between dehydroabietic acid and OH radicals under different atmospheric conditions

\begin{tabular}{|c|c|c|c|c|c|}
\hline Reaction conditions & & & & $\begin{array}{l}\text { Second-order rate } \\
\text { constant }\left(k_{2}, \mathrm{~cm}^{3}\right. \\
\left.\text { molecule }^{-1} \mathrm{~s}^{-1}\right)\end{array}$ & $\begin{array}{l}\text { Atmospheric } \\
\text { lifetime }^{a} \text { (days) }\end{array}$ \\
\hline $\begin{array}{l}\text { Pure dehydroabietic } \\
\text { acid (DHAA) }\end{array}$ & $\begin{array}{l}\text { DHAA-OH reaction } \\
\text { under different OH } \\
\text { concentrations } \\
\text { Literature results for } \\
\text { DHAA in the gas phase } \\
\text { Temperature effect }{ }^{c}\end{array}$ & $\begin{array}{l}\begin{array}{l}\text { OH concentration } \\
\left.\text { (molecule }^{b} \mathrm{~cm}^{-3}\right)^{63,70}\end{array} \\
\text { AOPWIN estimation } \\
\text { Quantum chemical } \\
\text { calculations }^{49}\end{array}$ & $\begin{array}{l}(2.05 \pm 0.06) \times 10^{7} \\
(2.38 \pm 0.08) \times 10^{7} \\
(2.99 \pm 0.10) \times 10^{7} \\
\text { Average }\end{array}$ & $\begin{array}{l}(5.69 \pm 0.84) \times 10^{-12} \\
(5.85 \pm 0.66) \times 10^{-12} \\
(5.62 \pm 0.51) \times 10^{-12} \\
(5.72 \pm 0.87) \times 10^{-12} \\
2.73 \times 10^{-11} \\
8.9 \times 10^{-12} \\
(3.90 \pm 0.69) \times 10^{-12} \\
(4.80 \pm 0.47) \times 10^{-12} \\
(5.10 \pm 0.54) \times 10^{-12} \\
(5.62 \pm 0.51) \times 10^{-12} \\
(6.16 \pm 0.47) \times 10^{-12} \\
(5.44 \pm 0.51) \times 10^{-12} \\
(5.61 \pm 0.32) \times 10^{-12} \\
(5.64 \pm 0.31) \times 10^{-12} \\
(5.32 \pm 0.41) \times 10^{-12}\end{array}$ & $\begin{array}{l}- \\
- \\
2.5 \pm 0.3 \\
0.5 \\
1.6 \\
3.7 \pm 0.6 \\
3.0 \pm 0.3 \\
2.8 \pm 0.3 \\
2.6 \pm 0.2 \\
2.3 \pm 0.2 \\
2.9 \pm 0.3 \\
2.8 \pm 0.2 \\
2.8 \pm 0.2 \\
2.9 \pm 0.2\end{array}$ \\
\hline Mixed samples $^{e}$ & $\begin{array}{l}\text { DHAA- }\left(\mathrm{NH}_{4}\right)_{2} \mathrm{SO}_{4} \\
\text { DHAA/soot } \\
\left(\mathrm{NH}_{4}\right)_{2} \mathrm{SO}_{4}-\mathrm{DHAA} / \text { soot }\end{array}$ & & & $\begin{array}{l}(4.58 \pm 0.95) \times 10^{-12} \\
(3.30 \pm 0.79) \times 10^{-12} \\
(3.52 \pm 0.91) \times 10^{-12}\end{array}$ & $\begin{array}{l}3.2 \pm 0.5 \\
4.4 \pm 0.8 \\
4.1 \pm 0.8\end{array}$ \\
\hline
\end{tabular}

${ }^{a}$ Assuming the typical concentration for $12 \mathrm{~h}$ average value of $\mathrm{OH}$ to be $1.6 \times 10^{6}$ molecules $\mathrm{cm}^{-3} \cdot{ }^{b}$ Experimental condition: $\mathrm{RH}=40 \%$, temperature $=25{ }^{\circ} \mathrm{C}^{c}{ }^{c}$ Experimental condition: $[\mathrm{OH}]=(2.99 \pm 0.10) \times 10^{7}$ molecules cm ${ }^{-3}, \mathrm{RH}=40 \%{ }^{d}$ Experimental condition: $[\mathrm{OH}]=(2.99 \pm$ $0.10) \times 10^{7}$ molecules cm ${ }^{-3}$, temperature $=25^{\circ} \mathrm{C}^{\circ}{ }^{e}$ Experimental condition: $[\mathrm{OH}]=(2.99 \pm 0.10) \times 10^{7}$ molecules cm ${ }^{-3}, \mathrm{RH}=40 \%$, temperature $=25{ }^{\circ} \mathrm{C}$.

At $25{ }^{\circ} \mathrm{C}$, the $k_{2}$ values for DHAA-OH reactions were similar for different $\mathrm{OH}$ concentrations (Table 1), with an average of $5.72 \pm 0.87 \times 10^{-12} \mathrm{~cm}^{3}$ molecule $\mathrm{e}^{-1} \mathrm{~s}^{-1}$. This implies that the experimental conditions are controllable and repeatable. Under the same conditions, the measured $k_{2}$ for DHAA toward $\mathrm{OH}$ in this study is significantly $\left(P=3.94 \times 10^{-8}\right.$ at 0.95 confidence level in one-way ANOVA analysis) smaller than that of levoglucosan $\left(9.17 \pm 1.16 \times 10^{-12} \mathrm{~cm}^{3}\right.$ molecule ${ }^{-1} \mathrm{~s}^{-1}$ at $25{ }^{\circ} \mathrm{C}$ and $40 \%$ RH). ${ }^{59}$ The difference between the measured $k_{2}$ of DHAA and levoglucosan highlights the role of structure in reactivity of organics to $\mathrm{OH}$. Using the Atmospheric Oxidation Program for Microsoft Windows (AOPWIN) model, which is based on structure-activity relationship (SAR) methods developed by Atkinson and coworkers, ${ }^{51,72}$ the $k_{2}$ of DHAA in the gas phase was estimated to be $2.73 \times 10^{-11} \mathrm{~cm}^{3}$ molecule $\mathrm{s}^{-1}$, whereas it was calculated to be $8.9 \times 10^{-12} \mathrm{~cm}^{3}$ molecule ${ }^{-1} \mathrm{~s}^{-1}$ using quantum chemical calculations. ${ }^{49}$ The average rate constant for the heterogeneous reaction between DHAA and $\mathrm{OH}$ radicals measured in this study is lower than the values calculated by both the quantum chemical program and the AOPWIN model. For levoglucosan, although the measured $k_{2}$ from our previous study shows good agreement with the chamber experiment result $\left((1.1 \pm 0.5) \times 10^{-11} \mathrm{~cm}^{3}\right.$ molecule $\left.{ }^{-1} \mathrm{~s}^{-1}\right),{ }^{36}$ it is below the result obtained by SAR calculation $\left(5.28 \times 10^{-11} \mathrm{~cm}^{3} \text { molecule }{ }^{-1} \mathrm{~s}^{-1}\right)^{73}$ and much higher than that obtained using quantum chemical calculations $\left(2.21 \times 10^{-13} \mathrm{~cm}^{3}\right.$ molecule $\left.{ }^{-1} \mathrm{~s}^{-1}\right) .{ }^{74}$ A recent study reported that the AOPWIN model overestimates the secondorder rate constant of the reaction of organic aerosol with $\mathrm{OH}$ in the particle phase ${ }^{75}$ which is consistent with results of the present study. The results obtained from this study also imply that the lifetime of organics might be underestimated using gas-phase kinetic data (SAR-based $k_{2}$ ); however, this requires confirmation by field measurements in remote regions. If these compounds can be observed in remote areas where the sources of the compound does not exist, then this would imply that its lifetime is long enough for transfer to such areas.

\section{Effect of temperature}

To investigate the effect of different temperatures, the temperature of the system was regulated at $5{ }^{\circ} \mathrm{C}, 15{ }^{\circ} \mathrm{C}, 20{ }^{\circ} \mathrm{C}, 25{ }^{\circ} \mathrm{C}$ and $30{ }^{\circ} \mathrm{C}$ under a constant $\mathrm{RH}$ of $40 \%$. Temperatures under $5{ }^{\circ} \mathrm{C}$ might cause some water vapor condensation on the surface of the sample holder, with the potential for errors in measurements of DHAA concentration. Thus, experiments at temperature lower than $5{ }^{\circ} \mathrm{C}$ were not performed in this study. The concentration of $\mathrm{OH}$ radical was adjusted to $2.99 \pm 0.10 \times$ $10^{7}$ molecules $\mathrm{cm}^{-3}$ and all the experiments were conducted in the dark.

The kinetic data were determined by monitoring loss of DHAA concentration as a function of $\mathrm{OH}$ exposure. The changes in $[\mathrm{DHAA}] /[\mathrm{DHAA}]_{0}$ as a function of $\mathrm{OH}$ exposure under different temperatures at $40 \% \mathrm{RH}$ are shown in Fig. 3 . The lines are the exponential curve fitting results, from which the $k_{2}$ can be derived via eqn (2). The $k_{2}$ values calculated at different temperatures are listed in Table 1. From these results, degradation of dehydroabietic acid was significantly influenced by temperature. The $k_{2}$ increased from $3.90 \pm 0.69 \times 10^{-12} \mathrm{~cm}^{3}$ molecule ${ }^{-1} \mathrm{~s}^{-1}$ at $5{ }^{\circ} \mathrm{C}$ to $6.16 \pm 0.47 \times 10^{-12} \mathrm{~cm}^{3}$ molecule ${ }^{-1} \mathrm{~s}^{-1}$ at $30{ }^{\circ} \mathrm{C}$.

Fig. 4 shows the Arrhenius plot of the measured rate constants for the reaction between DHAA and $\mathrm{OH}$, for which the Arrhenius expression is $k_{2}=(8.9 \pm 1.9) \times 10^{-10} \exp [-(1508.2 \pm 64.2) / T]$ in units of $\mathrm{cm}^{3}$ molecule $\mathrm{s}^{-1}$. A positive temperature dependence 


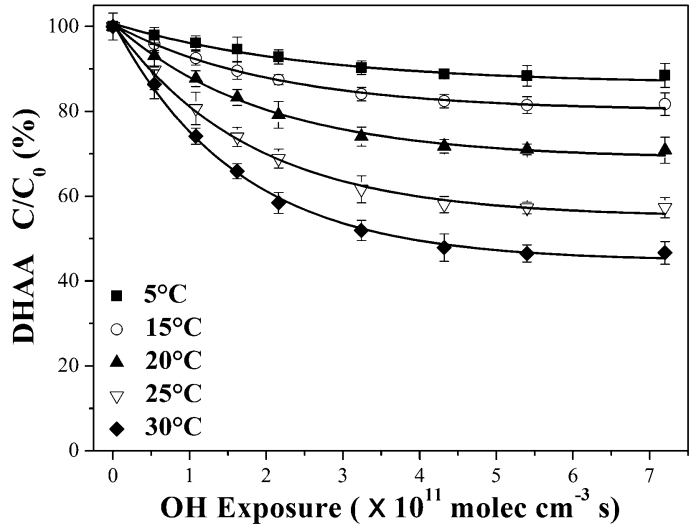

Fig. 3 Representative decays for dehydroabietic acid at different temperature with a constant relative humidity of $40 \%$ as a function of $\mathrm{OH}$ exposure ( $n=3$, error bars represent 1 standard deviation based on triplicate analyses).

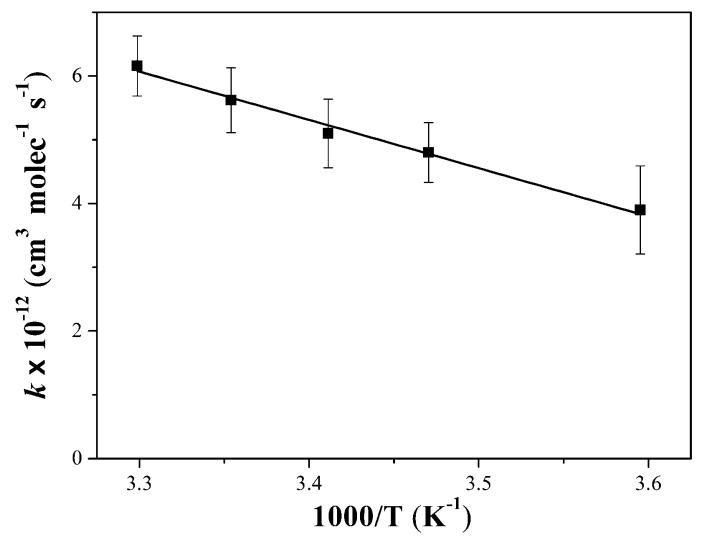

Fig. 4 Measured rate constants for the reaction between dehydroabietic acid and $\mathrm{OH}$ radical as a function of temperature.

was observed for this reaction, with the overall activation energy calculated to be $12.5 \pm 0.5 \mathrm{~kJ} \mathrm{~mol}^{-1}$. Some studies have found that temperature can either positively or negatively affect the reactions between different organic compounds and $\mathrm{OH}$ radicals. ${ }^{50,51}$ High temperature may affect gas/particle partitioning process, ${ }^{76}$ thus leading to more gas phase DHAA in the reactor. The phase state of particles has been found to play an important role in heterogeneous reactions. ${ }^{77}$ Transformation from the solid phase to semi-solid or liquid phase will promote heterogeneous reaction, because particle-phase diffusion becomes faster as a result of the lower viscosity of organic matter. However, the melting point of DHAA is 447-449 K, which is much higher than the highest temperature (303 K) in this study, so the narrow temperature range should have no influence on the phase state of the DHAA film. The positive temperature dependence of the rate constant means that there is an activation energy for the formation of the transition state and that the reactivity is promoted by higher temperatures. In a previous study, Bai et al. calculated the activation energies for DHAA-OH reaction with a large range between 0.97 and $18.08 \mathrm{~kJ} \mathrm{~mol}^{-1}$ for different elementary reactions with an average of $7.6 \pm 5.1 \mathrm{~kJ} \mathrm{~mol}^{-1} .{ }^{49}$ In this study, overall activation energy was measured. Although it is difficult to directly compare these activation energies, their tendencies are consistent, namely, higher temperatures promote this reaction. Similarly, for levoglucosan-OH reactions the overall activation energy was measured to be $16.0 \pm 2.2 \mathrm{~kJ} \mathrm{~mol}^{-1}, 59$ also implying a promotion effect by high temperature. ${ }^{37}$ This is analogous to the observed variation in DHAA and levoglucosan degradation with environmental temperature. DHAA and levoglucosan are two of the main biomass burning tracers, as degradation of both shows positive temperature dependence. More attention should be paid to $\mathrm{OH}$ oxidation of biomass burning tracers when source apportionment is carried out in different seasons.

\section{Effect of relative humidity}

To investigate the effect of different levels of $\mathrm{RH}$ on the degradation kinetics of DHAA by $\mathrm{OH}$, the $\mathrm{RH}$ of the system was adjusted to $20 \%, 40 \%, 60 \%$ and $80 \%$ under a constant temperature of $25{ }^{\circ} \mathrm{C}$. The concentration of $\mathrm{OH}$ radical was adjusted to $2.99 \pm 0.10 \times 10^{7}$ molecules $\mathrm{cm}^{-3}$. The changes in $[\mathrm{DHAA}] /[\mathrm{DHAA}]_{0}$ as a function of $\mathrm{OH}$ exposure under different $\mathrm{RH}$ at $25{ }^{\circ} \mathrm{C}$ are shown in Fig. 5 . The $k_{2}$ values for DHAA-OH reactions calculated by eqn (2) are listed in Table 1 . Results indicate that DHAA was rarely influenced by $\mathrm{RH}$ when temperature was fixed. It has been found that RH can positively or negatively influence reactions between $\mathrm{OH}$ and the organic particles. Some researchers have observed that increased $\mathrm{RH}$ will lower the viscosity of the amorphous aerosol particles and subsequently enhance $\mathrm{OH}$ uptake because particle-phase diffusion is feasible, ${ }^{78-80}$ whereas other results show that the $\mathrm{OH}$ uptake was suppressed at higher $\mathrm{RH}$ because of competitive co-adsorption of water, which will take up the reactive sites. ${ }^{52}$ Based on our previous study, degradation of levoglucosan by $\mathrm{OH}$ was influenced significantly by $\mathrm{RH}$ because of different layers of water cover on the surface of levoglucosan under different relative humidities. In this study, as the solubility of DHAA in water is rather low, variation of RH will not change the water content covering the surface of DHAA, thus has little influence on the degradation kinetics of DHAA when exposed to $\mathrm{OH}$.

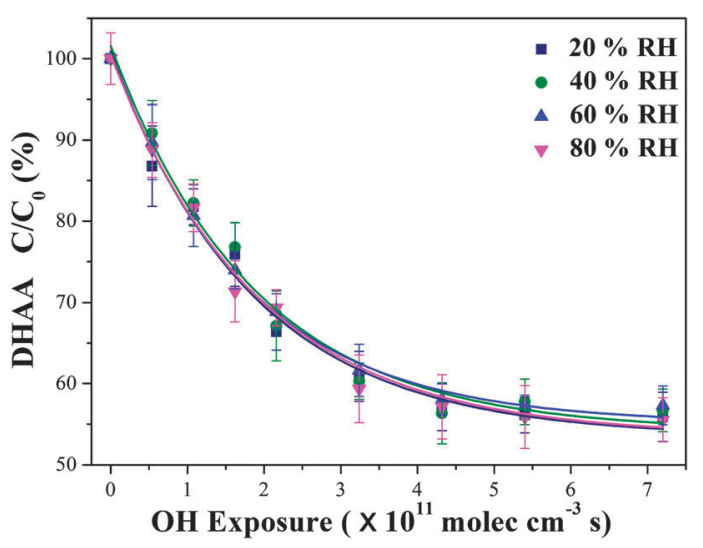

Fig. 5 Representative decays for dehydroabietic acid at different relative humidity with a constant temperature of $25{ }^{\circ} \mathrm{C}$ as a function of $\mathrm{OH}$ exposure. ( $n=3$, error bars represent 1 standard deviation based on triplicate analyses). 


\section{Effect of different mixing states}

To simulate different mixing states possibly present in the atmosphere, DHAA was mixed with $\left(\mathrm{NH}_{4}\right)_{2} \mathrm{SO}_{4}$, soot particles, and both $\left(\mathrm{NH}_{4}\right)_{2} \mathrm{SO}_{4}$ and soot. $\left(\mathrm{NH}_{4}\right)_{2} \mathrm{SO}_{4}$ and soot were chosen to mix with DHAA and simulate the ambient process for the following reasons. Firstly, sulfate contributes $30 \%$ of total atmospheric particles, which may mix with other species in the atmosphere. Secondly, as DHAA is mainly emitted from biomass combustion, it may mix with soot particles, thus mixtures of DHAA and soot are possible in the real atmosphere. Moreover, in the troposphere, heterogeneous reactions of trace gases, including $\mathrm{SO}_{2}$ and $\mathrm{NH}_{3}$, can take place on the soot surface. This results in internally mixed particles, which have been observed in field measurements. ${ }^{57,58}$ Therefore, similar to other organic components, which have been found to mix with $\left(\mathrm{NH}_{4}\right)_{2} \mathrm{SO}_{4}$ and soot, ${ }^{81-83}$ DHAA mixed with both soot and $\left(\mathrm{NH}_{4}\right)_{2} \mathrm{SO}_{4}$ may exist in the ambient air. As DHAA represents a series of compounds emitted from conifer wood combustion, which can be detected in relatively large quantities, ${ }^{5}$ the three mixing states represent well the real situation of DHAA.

The reactions between DHAA mixed samples and $\mathrm{OH}$ radicals were performed in the dark at $25{ }^{\circ} \mathrm{C}$ and $40 \% \mathrm{RH}$. The concentration of $\mathrm{OH}$ radical was $2.99 \pm 0.10 \times 10^{7}$ molecules $\mathrm{cm}^{-3}$. Fig. 6 shows the degradation curves for DHAA mixed samples, and the calculated $k_{2}$ values are listed in Table 1 . Through oneway analysis of variance (ANOVA), it was confirmed that the rate coefficients of the reactions between $\mathrm{OH}$ and DHAA, DHAA$\left(\mathrm{NH}_{4}\right)_{2} \mathrm{SO}_{4}$ and DHAA/soot do have significant differences, with $P<0.05$ (0.0399) at 0.95 confidence level. Therefore, degradation of DHAA by $\mathrm{OH}$ radical was significantly influenced by the mixing states. When mixed with $\left(\mathrm{NH}_{4}\right)_{2} \mathrm{SO}_{4}$ (corresponding to DHAA-AS), the rate constant of the degradation of DHAA by $\mathrm{OH}$ radical decreased to $4.58 \pm 0.9 \times 10^{-12} \mathrm{~cm}^{3}$ molecule ${ }^{-1} \mathrm{~s}^{-1}$ compared with pure DHAA. Based on semi-quantitative analysis carried out by SEM-EDX, the carbon content on the surface of DHAA-AS was determined to be $7.44 \%$ (by wt). The carbon content on the surface of DHAA-AS is higher than that of pure

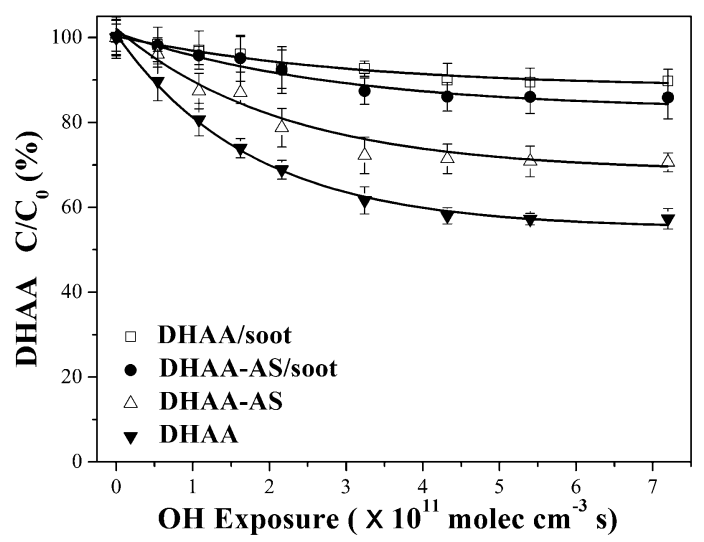

Fig. 6 Representative DHAA decays under different mixing states as a function of $\mathrm{OH}$ exposure at $25^{\circ} \mathrm{C}$ and $40 \% \mathrm{RH}(n=3$, error bars represent 1 standard deviation based on triplicate analyses).
$\left(\mathrm{NH}_{4}\right)_{2} \mathrm{SO}_{4}$, which means there is some DHAA on the surface of $\left(\mathrm{NH}_{4}\right)_{2} \mathrm{SO}_{4}$; but lower than hypothetical condition that DHAA were all on the surface of $\left(\mathrm{NH}_{4}\right)_{2} \mathrm{SO}_{4}$. This indicates that some DHAA may be encased by $\left(\mathrm{NH}_{4}\right)_{2} \mathrm{SO}_{4}$. Therefore, internally mixed $\left(\mathrm{NH}_{4}\right)_{2} \mathrm{SO}_{4}$ and DHAA was formed. The reduction of the rate constant might be related to the internally mixed $\left(\mathrm{NH}_{4}\right)_{2} \mathrm{SO}_{4}$ and DHAA, in which the $\left(\mathrm{NH}_{4}\right)_{2} \mathrm{SO}_{4}$ on the surface of the mixed sample may slightly inhibit diffusion of $\mathrm{OH}$ on the surface. When mixed with soot (corresponding to DHAA/soot), the degradation rate of DHAA by $\mathrm{OH}$ decreased to $3.30 \pm 0.79 \times$ $10^{-12} \mathrm{~cm}^{3}$ molecule ${ }^{-1} \mathrm{~s}^{-1}$, showing a more obvious inhibition effect compared with $\left(\mathrm{NH}_{4}\right)_{2} \mathrm{SO}_{4}$. As the surface area of soot is relatively high $\left(97.24 \mathrm{~m}^{2} \mathrm{~g}^{-1}\right)$, it is reasonable to infer that DHAA may enter the inner channels of soot, thus impeding contact between DHAA and $\mathrm{OH}$ radicals. On the other hand, soot is also reactive toward $\mathrm{OH},{ }^{84}$ and the completive reaction of the soot toward $\mathrm{OH}$ will reduce reaction between DHAA and $\mathrm{OH}$ because of the decrease in effective surface concentration of $\mathrm{OH}$. When mixed with both soot and $\left(\mathrm{NH}_{4}\right)_{2} \mathrm{SO}_{4}$ (corresponding to DHAA-AS/soot), as shown in Table 1 , the degradation rate of DHAA by $\mathrm{OH}$ was similar to that of the mixed sample DHAA/soot. This implies that reactivity of the soot on the surface toward $\mathrm{OH}$ might be the main reason for reduction of reactivity of DHAA in this complicated mixing state.

\section{Conclusions and atmospheric implications}

In this study, the degradation behaviors of DHAA toward $\mathrm{OH}$ radicals were measured using a flow reactor under different conditions to understand the atmospheric stability of DHAA. When exposed to $\mathrm{OH}$ radicals, conspicuous degradation of DHAA was observed. Temperature and the mixing state also play important roles in the degradation rate. The secondorder rate constant $\left(k_{2}\right)$ for degradation of pure DHAA in the particulate phase by $\mathrm{OH}$ was measured to be $5.72 \pm 0.87 \times$ $10^{-12} \mathrm{~cm}^{3}$ molecule ${ }^{-1} \mathrm{~s}^{-1}$ at $25{ }^{\circ} \mathrm{C}$ and $40 \% \mathrm{RH}$. This value is lower than those estimated in the gas phase. At $40 \% \mathrm{RH}$, the $k_{2}$ of pure DHAA increased with increasing temperature, as expressed in the Arrhenius equation $k_{2}=(8.9 \pm 1.9) \times$ $10^{-10} \exp [(-1508.2 \pm 64.2) / T]$, while $\mathrm{RH}$ had no significant impact at $25{ }^{\circ} \mathrm{C}$. Mixtures of DHAA with soot (DHAA/soot) showed more prominent inhibition of the degradation rate than mixtures with $\left(\mathrm{NH}_{4}\right)_{2} \mathrm{SO}_{4}$. When mixed with both soot and $\left(\mathrm{NH}_{4}\right)_{2} \mathrm{SO}_{4}$, no additional inhibition by $\left(\mathrm{NH}_{4}\right)_{2} \mathrm{SO}_{4}$ was observed compared with DHAA/soot.

$\mathrm{OH}, \mathrm{NO}_{3}, \mathrm{Cl}$ radicals and $\mathrm{O}_{3}$ are the main effective oxidants in the atmosphere, of which $\mathrm{OH}$ is considered to be the most dominant during the daytime for organics. ${ }^{72,85}$ Therefore, the rate coefficients obtained in this study can be used to calculate the atmospheric lifetime of DHAA exposed to $\mathrm{OH}$ radicals. The atmospheric lifetime of DHAA $(\tau)$ was calculated according to the following equation:

$$
\tau=\frac{1}{k_{2}[\mathrm{OH}]}
$$


Assuming a $12 \mathrm{~h}$ average $\mathrm{OH}$ concentration to be $1.6 \times$ $10^{6}$ molecules $\mathrm{cm}^{-3}$ during daytime $\left(25{ }^{\circ} \mathrm{C}\right.$ and $\left.101 \mathrm{kPa}\right),{ }^{86,87}$ the atmospheric lifetime of pure DHAA in the particle phase was calculated to be $2.5 \pm 0.3$ days. This value is prominently larger than the calculated lifetimes based on the rate constants in the gas phase, which suggests that modeling or quantum chemical calculations underestimate the lifetimes of organics in particulate matter. Under different environmental conditions, the lifetimes varied from $2.3 \pm 0.2$ to $4.4 \pm 0.8$ days, as shown in Table 1, indicating that temperature and mixing states have remarkable impacts on the degradation kinetics and lifetime of DHAA. In particular, soot particles may have a prominent effect on the degradation kinetics. Therefore, the degradation kinetics determined for pure DHAA should be the upper limit of that in the real troposphere. As DHAA is mainly produced during combustion, the kinetics data for DHAA on soot should be more realistic than those for pure DHAA.

It should be pointed out that the longest lifetime of DHAA measured in this study is still shorter than the residence time of aerosols in the troposphere. This means that the concentration of DHAA measured in field measurements for the purpose of source apportionment might have been underestimated in the past, thus introducing a negative error in source apportionment. For other sources, such as engine exhaust, Lambe et al. also pointed out that neglecting degradation of engine exhaust tracers ( $n$-alkanes, hopanes and steranes) by $\mathrm{OH}$ may lead to a significant error in source apportionment. ${ }^{41}$ As all these tracers show high reactivity towards $\mathrm{OH}$ radicals, understanding of the fate of these tracers in the atmosphere should be updated to ensure more effective results in source apportionment.

\section{Acknowledgements}

This research was supported by the National Natural Science Foundation of China (21190054, 51221892) and the Strategic Priority Research Program of the Chinese Academy of Sciences (XDB05010300, XDB05040100).

\section{Notes and references}

1 D. A. Knopf, S. M. Forrester and J. H. Slade, Phys. Chem. Chem. Phys., 2011, 13, 21050-21062.

2 M. Kanakidou, J. H. Seinfeld, S. N. Pandis, I. Barnes, F. J. Dentener, M. C. Facchini, R. Van Dingenen, B. Ervens, A. Nenes, C. J. Nielsen, E. Swietlicki, J. P. Putaud, Y. Balkanski, S. Fuzzi, J. Horth, G. K. Moortgat, R. Winterhalter, C. E. L. Myhre, K. Tsigaridis, E. Vignati, E. G. Stephanou and J. Wilson, Atmos. Chem. Phys., 2005, 5, 1053-1123.

3 F. Duan, K. He, Y. Ma, Y. Jia, F. Yang, Y. Lei, S. Tanaka and T. Okuta, Chemosphere, 2005, 60, 355-364.

4 J. Aldabe, D. Elustondo, C. Santamaría, E. Lasheras, M. Pandolfi, A. Alastuey, X. Querol and J. M. Santamaría, Atmos. Res., 2011, 102, 191-205.
5 R. M. Qadir, G. Abbaszade, J. Schnelle-Kreis, J. C. Chow and R. Zimmermann, Environ. Pollut., 2013, 175, 158-167.

6 J. C. Chow and J. G. Watson, Energy Fuels, 2002, 16, 222-260.

7 K. Saarnio, K. Teinila, M. Aurela, H. Timonen and R. Hillamo, Anal. Bioanal. Chem., 2010, 398, 2253-2264.

8 R. M. Healy, S. Hellebust, I. Kourtchev, A. Allanic, I. P. O'Connor, J. M. Bell, D. A. Healy, J. R. Sodeau and J. C. Wenger, Atmos. Chem. Phys., 2010, 10, 9593-9613.

9 D. Hu, Q. Bian, A. K. H. Lau and J. Z. Yu, J. Geophys. Res., 2010, 115, D16204.

10 V. A. Lanz, M. R. Alfarra, U. Baltensperger, B. Buchmann, C. Hueglin and A. S. H. Prevot, Atmos. Chem. Phys., 2007, 7, 1503-1522.

11 E. Stone, J. Schauer, T. A. Quraishi and A. Mahmood, Atmos. Environ., 2010, 44, 1062-1070.

12 E. A. Stone, D. C. Snyder, R. J. Sheesley, A. P. Sullivan, R. J. Weber and J. J. Schauer, Atmos. Chem. Phys., 2008, 8, 1249-1259.

13 Y. Chen, M. Zheng, E. S. Edgerton, L. Ke, G. Sheng and J. Fu, J. Geophys. Res., 2012, 117, D08304.

14 L. Lin, M. L. Lee and D. J. Eatough, J. Air Waste Manage. Assoc., 2010, 60, 3-25.

15 E. Vermote, E. Ellicott, O. Dubovik, T. Lapyonok, M. Chin, L. Giglio and G. J. Roberts, J. Geophys. Res., 2009, 114, D18205.

16 M. Fang, M. Zheng, F. Wang, K. L. To, A. B. Jaafar and S. L. Tong, Atmos. Environ., 1999, 33, 783-795.

17 K. Kawamura, Y. Izawa, M. Mochida and T. Shiraiwa, Geochim. Cosmochim. Acta, 2012, 99, 317-329.

18 J. S. Levine, W. R. Cofer, D. R. Cahoon and E. L. Winstead, Environ. Sci. Technol., 1995, 29, A120-A125.

19 B. R. T. Simoneit, Appl. Geochem., 2002, 17, 129-162.

20 P. M. Fine, G. R. Cass and B. R. T. Simoneit, Environ. Sci. Technol., 2002, 36, 1442-1451.

21 W. F. Rogge, L. M. Hildemann, M. A. Mazurek, G. R. Cass and B. R. T. Simoneit, Environ. Sci. Technol., 1998, 32, 13-22.

22 L. J. Standley and B. R. T. Simoneit, J. Atmos. Chem., 1994, 18, 1-15.

23 C. Gonçalves, C. Alves, A. P. Fernandes, C. Monteiro, L. Tarelho, M. Evtyugina and C. Pio, Atmos. Environ., 2011, 45, 4533-4545.

24 A. Vicente, C. Alves, A. I. Calvo, A. P. Fernandes, T. Nunes, C. Monteiro, S. M. Almeida and C. Pio, Atmos. Environ., 2013, 71, 295-303.

25 B. R. T. Simoneit and V. O. Elias, Mar. Pollut. Bull., 2001, 42, 805-810.

26 M. Xie, G. Wang, S. Hu, S. Gao, Q. Han, Y. Xu and J. Feng, Sci. Total Environ., 2010, 408, 5452-5460.

27 Y. Zhang, D. Obrist, B. Zielinska and A. Gertler, Atmos. Environ., 2013, 72, 27-35.

28 A. Caseiro and C. Oliveira, J. Environ. Monit., 2012, 14, 2261-2269.

29 M. Bergauff, T. Ward, C. Noonan and C. P. Palmer, Atmos. Environ., 2009, 43, 2938-2943. 
30 Z. Krivacsy, M. Blazso and D. Shooter, Environ. Pollut., 2006, 139, 195-205.

31 A. Leithead, S.-M. Li, R. Hoff, Y. Cheng and J. Brook, Atmos. Environ., 2006, 40, 2721-2734.

32 M. Mochida, K. Kawamura, P. Fu and T. Takemura, Atmos. Environ., 2010, 44, 3511-3518.

33 M. C. Pietrogrande, G. Abbaszade, J. Schnelle-Kreis, D. Bacco, M. Mercuriali and R. Zimmermann, Environ. Pollut., 2011, 159, 1861-1868.

34 A. L. Robinson, R. Subramanian, N. M. Donahue, A. BernardoBricker and W. F. Rogge, Environ. Sci. Technol., 2006, 40, 7811-7819.

35 J. J. Schauer, W. F. Rogge, L. M. Hildemann, M. A. Mazurek, G. R. Cass and B. R. T. Simoneit, Atmos. Environ., 1996, 30, 3837-3855.

36 C. J. Hennigan, A. P. Sullivan, J. L. Collett and A. L. Robinson, Geophys. Res. Lett., 2010, 37, L09806.

37 D. Hoffmann, A. Tilgner, Y. Iinuma and H. Herrmann, Environ. Sci. Technol., 2010, 44, 694-699.

38 S. H. Kessler, J. D. Smith, D. L. Che, D. R. Worsnop, K. R. Wilson and J. H. Kroll, Environ. Sci. Technol., 2010, 44, 7005-7010.

39 M. Shiraiwa, U. Poschl and D. A. Knopf, Environ. Sci. Technol., 2012, 46, 6630-6636.

40 J. H. Slade and D. A. Knopf, Phys. Chem. Chem. Phys., 2013, 15, 5898-5915.

41 A. T. Lambe, M. A. Miracolo, C. J. Hennigan, A. L. Robinson and N. M. Donahue, Environ. Sci. Technol., 2009, 43, 8794-8800.

42 E. A. Weitkamp, A. T. Lambe, N. M. Donahue and A. L. Robinson, Environ. Sci. Technol., 2008, 42, 7950-7956.

43 C. Coeur-Tourneur, A. Cassez and J. C. Wenger, J. Phys. Chem. A, 2010, 114, 11645-11650.

44 Q. Zhang, R. Gao, F. Xu, Q. Zhou, G. Jiang, T. Wang, J. Chen, J. Hu, W. Jiang and W. Wang, Environ. Sci. Technol., 2014, 48, 5051-5057.

45 Y. Sun, Q. Zhang, J. Hu, J. Chen and W. Wang, Chemosphere, 2015, 119, 626-633.

46 J. Dang, X. Shi, Q. Zhang, J. Hu, J. Chen and W. Wang, Sci. Total Environ., 2014, 490, 639-646.

47 N. S. Corin, P. H. Backlund and M. A. M. Kulovaara, Environ. Sci. Technol., 2000, 34, 2231-2236.

48 V. J. Martin, Z. Yu and W. W. Mohn, Arch. Microbiol., 1999, 172, 131-138.

49 J. Bai, X. Sun, C. Zhang, Y. Zhao and C. Gong, Chemosphere, 2013, 92, 933-940.

50 J. G. Calvert, A. Mellouki, J. Orlando, M. Pilling and T. Wallington, Mechanisms of atmospheric oxidation of the oxygenates, Oxford University Press, 2011.

51 R. Atkinson and J. Arey, Chem. Rev., 2003, 103, 4605-4638.

52 J. H. Slade and D. A. Knopf, Geophys. Res. Lett., 2014, 41, 5297-5306.

53 S. Zhou, A. K. Y. Lee, R. D. McWhinney and J. P. D. Abbatt, J. Phys. Chem. A, 2012, 116, 7050-7056.

54 C. L. Badger, P. T. Griffiths, I. George, J. P. Abbatt and R. A. Cox, J. Phys. Chem. A, 2006, 110, 6986-6994.
55 J. A. Kozinski and R. Saade, Fuel, 1998, 77, 225-237.

56 D. D. Weis and G. E. Ewing, J. Geophys. Res., 1999, 104, 21275-21285.

57 W. Li, L. Shao, R. Shen, S. Yang, Z. Wang and U. Tang, J. Air Waste Manage. Assoc., 2011, 61, 1166-1173.

58 W. Li, L. Shao, Z. Shi, J. Chen, L. Yang, Q. Yuan, C. Yan, X. Zhang, Y. Wang, J. Sun, Y. Zhang, X. Shen, Z. Wang and W. Wang, J. Geophys. Res., 2014, 119, 1044-1059.

59 C. Lai, Y. Liu, J. Ma, Q. Ma and H. He, Atmos. Environ., 2014, 91, 32-39.

60 J. Ma, Y. Liu and H. He, Atmos. Environ., 2010, 44, 4446-4453.

61 J. Ma, Y. Liu and H. He, Atmos. Environ., 2011, 45, 917-924.

62 M. C. Pietrogrande, D. Bacco and M. Mercuriali, Anal. Bioanal. Chem., 2010, 396, 877-885.

63 C. C. Chiueh, G. Krishna, P. Tulsi, T. Obata, K. Lang, S.-J. Huang and D. L. Murphy, Free Radical Biol. Med., 1992, 13, 581-583.

64 J. P. A. Neeft, M. Makkee and J. A. Moulijn, Fuel, 1998, 77, 111-119.

65 K. Villani, W. Vermandel, K. Smets, D. Liang, G. Van Tendeloo and J. A. Martens, Environ. Sci. Technol., 2006, 40, 2727-2733.

66 T. Berndt and S. Richters, Atmos. Environ., 2012, 47, 316-322.

67 L. F. Keyser, S. B. Moore and M. T. Leu, J. Phys. Chem., 1991, 95, 5496-5502.

68 G. M. Underwood, P. Li, H. Al-Abadleh and V. H. Grassian, J. Phys. Chem. A, 2001, 105, 6609-6620.

69 J. F. Widmann and E. J. Davis, J. Aerosol Sci., 1997, 28, 87-106.

70 B. Yao, T. Zhu and W. Lin, Environ. Chem., 2006, 25, $772-775$.

71 I. J. George and J. P. Abbatt, Nat. Chem., 2010, 2, 713-722.

72 R. Atkinson, Chem. Rev., 1985, 85, 69-201.

73 W. M. Meylan and P. H. Howard, Chemosphere, 1993, 26, 2293-2299.

74 J. Bai, X. Sun, C. Zhang, Y. Xu and C. Qi, Chemosphere, 2013, 93, 2004-2010.

75 Y. Liu, J. Liggio, T. Harner, L. Jantunen, M. Shoeib and S. M. Li, Environ. Sci. Technol., 2014, 48, 1041-1048.

76 X. Ding, X.-M. Wang and M. Zheng, Atmos. Environ., 2011, 45, 1303-1311.

77 H. Saathoff, K. H. Naumann, O. Möhler, A. M. Jonsson, M. Hallquist, A. Kiendler-Scharr, T. F. Mentel, R. Tillmann and U. Schurath, Atmos. Chem. Phys., 2009, 9, 1551-1577.

78 L. P. Chan and C. K. Chan, Aerosol Sci. Technol., 2012, 46, 236-247.

79 M. Kuwata and S. T. Martin, Proc. Natl. Acad. Sci. U. S. A., 2012, 109, 17354-17359.

80 Y. Liu, L. Huang, S. M. Li, T. Harner and J. Liggio, Atmos. Chem. Phys., 2014, 14, 12195-12207.

81 K. Adachi and P. R. Buseck, Atmos. Chem. Phys., 2008, 8, 6469-6481.

82 S. D. Brooks, M. E. Wise, M. Cushing and M. A. Tolbert, Geophys. Res. Lett., 2002, 29, 23-1-23-4. 
83 M. Schnaiter, H. Horvath, O. Möhler, K. H. Naumann, H. Saathoff and O. W. Schöck, J. Aerosol Sci., 2003, 34, 1421-1444. 84 C. P. Fenimore and G. W. Jones, J. Phys. Chem., 1967, 71, 593-597. 85 R. Atkinson, in Air Pollution, the Automobile, and Public Health, ed. D. Kennedy and R. Bates, National Academy Press, Washington, D. C., 1988, pp. 99-132.
86 R. Prinn, D. Cunnold, P. Simmonds, F. Alyea, R. Boldi, A. Crawford, P. Fraser, D. Gutzler, D. Hartley and R. Rosen, J. Geophys. Res., 1992, 97, 2445-2461.

87 R. Prinn, D. Cunnold, R. Rasmussen, P. Simmonds, F. Alyea, A. Crawford, P. Fraser and R. Rosen, Science, 1987, 238, 945-950. 